\title{
A PEDAGOGIA DO ENSINO DAS MODALIDADES ESPORTIVAS COLETIVAS E INDIVIDUAIS: UM ENSAIO TEÓRICO
}

\author{
Rodrigo Luiz Vancini, Universidade Federal do Espírito Santo - UFES, Vitória, Espírito \\ Santo - Brasil \\ Edson Castardeli Castardeli, Universidade Estadual de Campinas - UNICAMP, \\ Campinas, São Paulo - Brasil \\ Karine Jacon Sarro, Universidade Estadual de Campinas - UNICAMP, Campinas, São \\ Paulo - Brasil \\ Rafael Júlio Freitas Guina Fachina, Confederação Brasileira de Basketball, Rio de \\ Janeiro, Rio de Janeiro - Brasil \\ Marília Santos Andrade, Universidade Federal de São Paulo - UNIFESP, São Paulo, São \\ Paulo - Brasil \\ Claudio André Barbosa Lira - Universidade Federal de Goiás (UFG), Goiânia, Goiás - \\ Brasil
}

\section{RESUMO}

A pedagogia do esporte investiga a prática educativa pelo esporte. Os objetivos da pedagogia do esporte são apontar princípios norteadores e organizar, planejar e sistematizar procedimentos de ensino/aprendizagem/treinamento que auxiliem no desenvolvimento integral do ser humano. Além disso, seu conhecimento contribui para sistematizar e aperfeiçoar o ensino de diferentes modalidades esportivas coletivas e/ou individuais. Dessa forma, um ensaio teórico sobre a pedagogia do esporte, pautado nos principais conceitos necessários à prática diária da Educação Física, pode contribuir para que os profissionais da área aperfeiçoem a sua práxis.

Palavras-Chaves: Pedagogia; Esporte; Esporte coletivo; Esporte individual.

\section{PEDAGOGICAL TECHNIQUES TO TEACHING TEAM AND INDIVIDUAL SPORTS: A THEORETICAL ESSAY}

\begin{abstract}
The sport pedagogy investigates the educational practice by the sport. The goals of sport pedagogy are to guide, organize, plan, and systematize procedures for teaching/learning/training to assist the full development of humans. In addition, this knowledge contributes to systematize and improve the teaching of different collective and/or individual sports. Thus, a theoretical essay on sport pedagogy addressed in the key concepts necessary for the daily physical education practice can contribute for the refinement of professionals practice.

Conexões: revista da Faculdade de Educação Física da UNICAMP, Campinas, v. 13, n. 4, p. 137-154, out./dez. 2015. ISSN: 1983-9030.
\end{abstract}


Key-Words: Pedagogy; Sport; Team sports; Individual sport.

\section{LA PEDAGOGÍA DE LA ENSEÑANZA DE DESPORTES DE EQUIPO Y INDIVIDUALES: UN ENSAYO TEÓRICO}

\section{RESUMEN}

La pedagogía del deporte ayuda a investigar la práctica educativa del deporte. Los objetivos de la pedagogía del deporte son organizar, planificar y sistematizar los procedimientos de enseñanza/aprendizaje/formación para ayudar en el desarrollo integral de los seres humanos Además, su conocimiento contribuye a sistematizar y mejorar la enseñanza de las diferentes disciplinas deportivas colectivas y/o individuales. Así, un ensayo teórico sobre el pedagogía deportiva gobernado en los conceptos clave necesarios para la práctica diaria de la educación física puede contribuir a los profesionales a refinar su práctica.

Palabras-Clave: Educación; Deporte; Deportes de equipo; Deporte individual. 


\section{PRIMEIRAS PALAVRAS}

A pedagogia é a ciência que propõe formas de intervenção metodológica e organizativa, nos âmbitos da atividade educativa, implicados na transmissão/assimilação ativa de saberes e modos de ação. ${ }^{1-6}$

Nesse contexto, a pedagogia do esporte é definida como o campo do conhecimento que investiga a prática educativa, especificamente pelo esporte. A abordagem pedagógica do esporte tem associação tanto com a pedagogia geral (aspecto educativo do esporte), à qual se liga pela questão da aprendizagem, formação, desenvolvimento e educação, quanto com as ciências do esporte (aspecto motriz), às quais se liga pelo corpo e movimento. ${ }^{1-6}$

A pedagogia do esporte está balizada por dois princípios integrados, que servem como ponto de partida para o ensino do esporte: o principio técnico-tático e o sócio-educativo. O primeiro tem por objetivo trabalhar aspectos físicos, técnicos e táticos da prática esportiva, centrando atenção nas questões: Como? Quando? Para quem? E qual a melhor forma de ensinar e treinar esporte? ${ }^{6-7}$

Já o princípio sócio-educativo ensina a lidar com valores e modos de comportamento. Num mundo onde prevalece a indiferença, as relações superficiais e o individualismo, o esporte poderá influenciar na transformação desse contexto e contribuir para a vida do aluno enquanto mais consciente de seus direitos e deveres. ${ }^{7}$

Os objetivos da pedagogia do esporte estão centrados na pessoa e na sua relação com o ambiente esportivo. Nesse sentido, a pedagogia do esporte se incumbe de apontar princípios norteadores pedagógicos, organizar, planejar, propor, sistematizar, executar, transformar e avaliar procedimentos e métodos de ensino-aprendizagem para que seja possível auxiliar no desenvolvimento integral do ser humano. Além disso, contribui para que a prática sistemática de diferentes modalidades esportivas (coletivas e/ou individuais) melhore, por variadas razões, o estado de saúde e a qualidade de vida dos praticantes. ${ }^{6}$ Portanto, um método de ensino pautado na pedagogia do esporte pode garantir a oportunidade de participação efetiva para todos os sujeitos, despertar o prazer e o interesse Conexões: revista da Faculdade de Educação Física da UNICAMP, Campinas, v. 13, n. 4, p. 137-154, out./dez. 2015. ISSN: 1983-9030. 
pelo esporte em diversos níveis (seja como aluno, educador, atleta ou espectador), levar a uma prática voltada para a saúde ao longo da vida, educar para a moral autônoma individual e coletiva (direitos e deveres). Além disso, pode i) contribuir para o estabelecimento de relações pessoais de valor, tais como cooperação, empatia, ética e respeito, que sejam transferidas e relacionadas com a vida cotidiana, ii) preparar o aluno para conviver com o fenômeno esportivo de forma reflexiva e autônoma de forma que saiba gerir sua prática esportiva, iii) diversificar a prática esportiva e buscar o desenvolvimento integral do aluno, estimulando suas múltiplas competências e inteligências para que possa desenvolver todo o seu potencial para a vida e o esporte. ${ }^{6-7}$

Dessa forma, o objetivo do presente trabalho é apresentar um ensaio teórico sobre conceitos que balizam o ensino de modalidades individuais e coletivas. Esse ensaio foi pautado na experiência de ensino (sala de aula) e prática (quadra e outros cenários esportivos) de modalidades individuais e coletivas para turmas de licenciatura e bacharelado em Educação Física.

\section{AS MANIFESTAÇÕES E FINALIDADES DO FENÔMENO ESPORTE}

O esporte pode ser entendido como uma solicitação muscular com caráter de competição ou com a finalidade de desempenho pessoal destacado. Tem finalidade lúdica ou de competição. Também pode ser compreendido como manifestação social, presente em nossa cultura, em todas as fases da vida, e considerado fenômeno de múltiplas possibilidades, o qual deve ser acessível a todo cidadão. ${ }^{7-8}$

Dentre as finalidades do esporte temos: esporte de excelência, esporte de lazer; esporte relacionado à saúde, à qualidade de vida e a fins terapêuticos; e o esporte escolar. Vale destacar que o esporte no âmbito escolar prioriza a transmissão de valores, atitudes e habilidades e auxilia na formação do caráter e na descoberta das possibilidades de movimento. Além disso, procura transmitir a cultura esportiva e formar cidadãos que saibam utilizar as diversas práticas corporais ao longo da vida. ${ }^{7-8}$

Complementando as finalidades do esporte, temos a Lei nº 9.615, de 24 de março de 1998 que no capítulo III, artigo $3^{\circ}$, traz que o esporte pode ser reconhecido em qualquer das seguintes manifestações: $:^{7: 9}$

Conexões: revista da Faculdade de Educação Física da UNICAMP, Campinas, v. 13, n. 4, p. 137-154, out./dez. 2015. ISSN: 1983-9030. 
I - esporte educacional, praticado nos sistemas de ensino e em formas assistemáticas de educação, evitando-se a seletividade, a hipercompetitividade de seus praticantes, com a finalidade de alcançar o desenvolvimento integral do indivíduo e a sua formação para o exercício da cidadania e a prática do lazer;

II - esporte de participação, de modo voluntário, compreendendo as modalidades esportivas praticadas com a finalidade de contribuir para a integração dos praticantes na plenitude da vida social, na promoção da saúde e educação e na preservação do meio ambiente;

III - esporte de rendimento, praticado segundo normas gerais desta Lei e regras de prática desportiva, nacionais e internacionais, com a finalidade de obter resultados e integrar pessoas e comunidades do País e estas com as de outras nações.

\section{PLURALIDADE E SIGNIFICADO DO FENÔMENO ESPORTE}

O esporte pode envolver a participação de diferentes tipos de sujeitos. No momento em que novos significados são atribuídos ao esporte, mais pessoas se sentem atraídas por esse fenômeno tão importante para o desenvolvimento da nossa sociedade. Para que todos tenham acesso ao esporte de forma segura, benéfica, organizada e prazerosa, é fundamental o respeito às particularidades e aos diferentes significados da sua prática pelos diferentes tipos de sujeitos, os quais devem ter sua individualidade biológica e necessidades respeitadas. ${ }^{8}$ É preciso tratar o fenômeno esporte em toda a sua pluralidade, já que o mesmo é um fenômeno social de múltiplas possibilidades e que envolve diferentes cenários de prática. Por exemplo, com relação aos cenários, temos os formais, como, escola, universidade e faculdade e os não formais como clubes, praças públicas e "escolinhas” de esporte. ${ }^{6-7}$

Ainda, o fenômeno esporte envolve o trabalho integrado de equipe formada por diferentes profissionais e pela perspectiva das ciências do esporte inclui uma serie de abordagens e disciplinas. Dentre as disciplinas envolvidas (todas aplicadas ao esporte) temos a sociologia, a filosofia, a biomecânica, a psicologia, a história, a economia e a medicina. ${ }^{6,8}$ 
$\mathrm{Na}$ perspectiva dos diversos significados do esporte, é preciso evitar uma prática reducionista, que busca o desempenho máximo e que reduz a prática de esporte apenas à participação de atletas profissionais, com a finalidade da busca de talentos esportivos. ${ }^{7}$

Para opor-se a esse reducionismo e dar um tratamento pedagógico aos processos de ensino/vivência/aprendizagem/treinamento do esporte é necessário refletir e discutir questões como: Em que medida o esporte poderá contribuir de forma significativa para o desenvolvimento global do sujeito e de que forma o sujeito poderá contribuir para o desenvolvimento da sociedade? Qual a prática realizada? Quem está praticando? Por que está praticando? Onde será realizada a prática? ${ }^{7}$

A resposta, a essas questões são fundamentais para entender as inúmeras possibilidades e significados do fenômeno esporte, seja para desenvolver um referencial pedagógico das práticas esportivas ou para traçar em conjunto com alunos/jogadores os objetivos do programa. No momento em que novos significados são atribuídos ao esporte, mais pessoas se sentem atraídas por esse fenômeno tão importante para o desenvolvimento da sociedade. Em resumo, uma visão ampliada pelo profissional de educação física, para a compreensão do fenômeno esporte, deve considerar e identificar quatro aspectos: ${ }^{6-7}$

Cenários: entender o contexto em que ocorre a prática esportiva;

Personagens: respeitar as individualidades;

Significados: motivação para a prática da modalidade esportiva preferida;

$\checkmark$ Modalidades: conhecer as especificidades da modalidade praticada e suas particularidades.

Esses aspectos devem ser trabalhados de forma integrada uma vez que estão relacionados entre si. Por fim, cabe ao profissional de Educação Física criar e fomentar um ambiente cooperativo entre todos aqueles que participam de uma forma ou de outra do fenômeno esporte, a saber: professores, técnicos, alunos, dirigentes, familiares, jogadores, mídia e expectadores. ${ }^{6-7}$

Conexões: revista da Faculdade de Educação Física da UNICAMP, Campinas, v. 13, n. 4, p. 137-154, out./dez. 2015. ISSN: 1983-9030. 


\section{ENSINO DO ESPORTE E CONCEITOS TRABALHADOS NAS DIFERENTES FASES}

Outro aspecto importante no ensino de modalidades esportivas é respeitar os períodos e fases do processo de desenvolvimento de formação para o esporte, a saber: estimulação motora; prática motora; e especialização motora. ${ }^{1,10-12}$

No contexto do ensino e da aprendizagem de modalidades esportivas alguns conceitos são importantes: $:^{1-5,10}$

$\checkmark$ Método: conjunto de procedimentos adequados para alcançar determinados fins (caminho a ser percorrido para ensinar);

$\checkmark$ Didática: conjunto de recursos técnicos (ou estratégias) que tem como objetivo dirigir a aprendizagem do educando e que objetiva levá-lo a atingir um estado de maturidade que o capacite a encontrar-se com a realidade, de maneira consciente, equilibrada e eficiente e nela agir como cidadão responsável;

$\checkmark$ Metodologia: é o estudo dos métodos. Por exemplo, metodologia do ensino da ginástica, do basquetebol e etc.;

$\checkmark$ Metodologia de ensino: estudo de um conjunto de meios dispostos convenientemente para dirigir a aprendizagem do educando. Pode dirigir a aprendizagem de qualquer modalidade esportiva. Todo método de ensino deve estar em perfeita adequação com o ideal e a realidade do educando;

$\checkmark$ Sequência pedagógica: centralizada apenas no método para ensino ou treinamento do esporte destacando, quase exclusivamente, aspectos físicos e técnicos da prática;

$\checkmark$ Procedimento pedagógico: conjunto de ações que visam não só aos aspectos do movimento, mas também aos aspectos sócio-educativos do esporte, ou seja, potencializam as possibilidades educacionais, contribuindo para a formação integral dos sujeitos; toda a ação intencional, toda a intervenção pensada e organizada previamente pelo professor, para facilitar e aperfeiçoar o processo de ensino/vivência/aprendizagem. Além disso, a melhora do ambiente esportivo também é um procedimento pedagógico. 


\section{ALGUNS CONCEITOS FUNDAMENTAIS PARA O ENSINO DE MODALIDADES ESPORTIVAS COLETIVAS}

Uma modalidade esportiva é composta por um conjunto de ações motoras direcionadas a um determinado objetivo. No que se refere às modalidades coletivas temos como as mais tradicionais, em nosso país, o futebol de campo, o futsal, voleibol, basquetebol e handebol. Pelo fato de todas possuírem uma bola, um espaço de jogo, parceiros com os quais se joga, adversários, um alvo a atacar e, de forma complementar, um alvo a defender, e regras específicas, essas modalidades podem ser agrupadas em uma única categoria, o esporte coletivo ou jogo esportivo coletivo. ${ }^{13}$ Outras características comuns ao esporte coletivo é que possuem uma unidade de jogo, caráter de imprevisibilidade das ações motoras, ações cooperativas entre companheiros, rápidas tomadas de decisões e participação de múltiplas inteligências. As múltiplas inteligências que poderiam ser trabalhadas e desenvolvidas através da prática de modalidades esportivas coletivas seriam: corporal-cinestésica, verballinguística, lógica-matemática, espacial, musical, naturalista, interpessoal e intrapessoal. ${ }^{6}$

Ainda, as modalidades esportivas coletivas podem ser entendidas como um confronto entre duas equipes, que se dispõem pelo terreno de jogo e se movimentam de forma particular, com o objetivo de vencer, alternando-se em situações de ataque e defesa. Estas modalidades são dinâmicas e complexas, exigindo de seus praticantes, habilidades motoras básicas e específicas e todas as capacidades físicas bem como múltiplas competências, respeito aos colegas de equipe e adversários e domínio de uma lógica técnica e tática. ${ }^{6,13}$

Para a obtenção de sucesso na progressão da bola e da equipe em direção ao alvo adversário são necessárias algumas ações individuais e coletivas, tais como criar linhas de passe, colocação individual em espaços onde a bola possa chegar e desmarcação em relação aos jogadores adversários. Para que esse princípio operacional ocorra, os sujeitos devem aliar técnica e tática. A técnica é o domínio do gesto (“modo de fazer”) por meio da repetição já a tática são as “razões do fazer”. 6-7,13

Os princípios gerais das modalidades coletivas são: ${ }^{6-7,13}$

Conexões: revista da Faculdade de Educação Física da UNICAMP, Campinas, v. 13, n. 4, p. 137-154, out./dez. 2015. ISSN: 1983-9030. 
$\checkmark$ Atacar: cujo objetivo é a conservação individual e coletiva da bola, progressão da equipe e da bola em direção ao alvo adversário e finalização da jogada, visando à obtenção de ponto;

$\checkmark$ Defender: cujo objetivo é a recuperação da bola, impedir o avanço da equipe contrária e da bola em direção ao próprio alvo e a proteção do alvo visando impedir a finalização da equipe adversária;

$\checkmark$ Respeitar princípios técnicos: o modo de fazer, execução do gesto esportivo. A palavra “técnica” tradicionalmente é usada como sinônimo de movimento correto;

$\checkmark$ Seguir princípios táticos: as razões do fazer, ações coordenadas entre o indivíduo e o grupo. As habilidades táticas incluem, principalmente, ações voltadas para jogar coletivamente, ou seja, a capacidade de tomar decisões sobre o que fazer levando em consideração as circunstâncias do jogo.

Por fim, as modalidades coletivas basicamente possuem: i) um sistema defensivo cujo objetivo é recuperar a bola, impedir o avanço da equipe contrária e da bola em direção ao próprio alvo e a proteção do alvo visando impedir a finalização da equipe adversária; ii) um sistema ofensivo cujo objetivo é a conservação individual e coletiva da bola, progressão da equipe e da bola em direção ao alvo adversário e finalização da jogada, visando à obtenção do ponto; iii) um sistema de transição que é a passagem do sistema defensivo para o ofensivo ou vice-versa. ${ }^{6-7,13}$

\section{ESTRATÉGIAS DE ENSINO DAS MODALIDADES ESPORTIVAS COLETIVAS}

Quanto aos facilitadores e possíveis estratégias para o ensino das modalidades coletivas temos: exercícios analíticos e exercícios sincronizados, jogos e brincadeiras, e situações de jogo. ${ }^{6-7,13}$

Com relação aos exercícios analíticos, estes estão relacionados com o aperfeiçoamento da técnica e sua execução está, muitas vezes, desvinculada da situação real de jogo. Em geral, são realizados individualmente e visam ao aprimoramento de um único fundamento. Por exemplo, temos o arremesso (lance livre basquetebol), o saque (voleibol), o chute (futebol) e o arremesso (handebol). ${ }^{6-7,13}$

Conexões: revista da Faculdade de Educação Física da UNICAMP, Campinas, v. 13, n. 4, p. 137-154, out./dez. 2015. ISSN: $1983-9030$ 
Já os exercícios sincronizados tratam-se da utilização de dois ou mais fundamentos em um mesmo exercício, a fim de aprimorá-los. Assemelham-se aos exercícios analíticos, mas visam aos vários fundamentos do esporte e envolvem mais de um aluno na sua execução. A dinâmica e a aproximação que tem com jogo são os pontos positivos desta estratégia. ${ }^{6-7}$, 13

Outra estratégia para ensino dos esportes coletivos são as brincadeiras. As brincadeiras são atividades e jogos muito presentes na cultura popular infantil que permitem trabalhar com rigor os aspectos técnicos dos gestos esportivos, além de acentuarem o caráter lúdico da prática esportiva. As mesmas podem aproximar as ações e os deslocamentos motores daquilo que é realizado no jogo real. ${ }^{6-7,13}$

Temos ainda as situações de jogo que simulam as situações reais de jogo em momentos isolados, por exemplo, 1x1, 2x2, 3x3, 4x4, 2x1 (superioridade numérica/inferioridade numérica), 3x2, 4x3 e etc.; os jogos pré-esportivos que se aproximam dos jogos esportivos, no entanto, geralmente têm regras mais simples e com caráter lúdico; bem como os jogos reduzidos que são jogos em que os espaços e número de jogadores são reduzidos. A vantagem dos jogos reduzidos é proporcionar ao sujeito uma participação mais efetiva no jogo e seu contato com a bola, devido à presença de um menor número de jogadores, além de facilitar as intervenções do professor/treinador e de manter características táticas de situações de jogo. ${ }^{6-7,13}$

Finalmente, temos o jogo formal que é o jogo da modalidade, em si. Pode ser utilizado como uma forma de ensinar o jogo, especialmente quando o professor/treinador está atento aos conflitos existentes no mesmo e intervém constantemente no intuito de esclarecer as dúvidas e mostrar inúmeras situações-problema, apontando pistas para suas soluções a partir das contribuições dos alunos. ${ }^{6-7,13}$

O jogo como metodologia de ensino das modalidades esportivas coletivas 
O jogo, sempre que possível, deve estar presente nas sessões de prática esportiva, já que o mesmo é um facilitador pedagógico, pois permite a simulação lúdica da realidade e estimula respostas criativas (individuais e coletivas). Além disso, estimula a motivação, a participação e a alegria, a cooperação e as construções para o jogo e para a vida. Também, aprimora o entendimento da lógica técnico-tática nos jogos esportivos coletivos, permite a vivência de aspectos físicos, técnicos e táticos, proporciona gosto pela prática e é imprevisível e desafiador. ${ }^{13}$

No jogo aparecem constantemente problemas, que estimulam respostas criativas e hábeis, individuais e coletivas, o que facilita a cooperação e importantes construções para o jogo e para a vida. Permite, ainda, ao aluno compreender a complexidade dos jogos coletivos de forma autônoma, inclusiva e diversificada. O ensino pelo jogo é muito dinâmico, pois permite uma série de adaptações e infinitas vivências de acordo com os objetivos traçados com a modificação, adaptação e alteração: de regras (sistema de pontuação), do espaço (dimensões espaciais do jogo), do número e da atuação dos jogadores (posições de jogadores), das especificações dos materiais (dimensões, textura, oficiais e não oficiais), do tempo (limitar o tempo para as ações motoras), do número de materiais (variação do número de bolas), das ações (restringir ou favorecer determinadas ações de um jogo), e da emoção e envolvimento dos participantes. ${ }^{6-7,13}$

É importante destacar que o ensino do jogo pode preceder o ensino do esporte e o mesmo pode ser ensinado de forma gradual e progressiva e de acordo com fases práticas, ${ }^{6-7,13}$ a saber:

$\checkmark \quad$ Fase 1, na qual se exercita as habilidades simples sem oposição e a capacidade de controle do objeto de jogo;

$\checkmark$ Fase 2, na qual se exercita a combinação de habilidades sem oposição e se estabelece relações motoras de cooperação com outros;

$\checkmark \quad$ Fase 3, na qual se exercita situações de oposição simplificada e táticas básicas ofensivas e defensivas;

$\checkmark \quad$ Fase 4, que é a prática em situações semelhantes ao jogo formal e formas modificadas de jogo com especialização de funções (posicionamento). 
Para exemplificar o exposto, ilustraremos resumidamente o que compõe o jogo de voleibol. O voleibol é um jogo de oposição-colaboração, no qual a ação de uma equipe se desenvolve em espaço separado daquele do adversário. Essa condição promove alternância sistemática entre o ataque e defesa. Essa modalidade se diferencia das demais modalidades coletivas (futebol de campo, futsal, basquetebol, handebol e etc.), uma vez que no voleibol a equipe atua com a posse da bola na defesa. Nas outras modalidades a atuação é feita com a posse da bola no ataque e sem a posse da bola na defesa. Além dessa diferença, encontrase a lógica do jogo que é constituída por meio da ordem sequencial dos seus seis fundamentos: saque, passe, ataque, levantamento, bloqueio e defesa. ${ }^{6}$

A prática de qualquer das manifestações do esporte objetiva dar oportunidade ao sujeito conhecer, aprender e utilizar o mesmo de acordo com seus interesses pessoais. Quanto mais diversificada a vivência dos gestos motores, melhor para o aprendiz, que terá repertório mais rico e variado e mais possibilidades neuromotoras ao longo de toda vida. ${ }^{6,10}$

\section{ESTRATÉGIAS DE ENSINO DAS MODALIDADES ESPORTIVAS INDIVIDUAIS}

Com relação às modalidades individuais temos uma diversidade muito grande de práticas cada uma delas com as suas particularidades e especificidades e, portanto, com processos pedagógicos diferenciados. Portanto é mais difícil de fazer as generalizações. Dentre as mais tradicionais temos o atletismo, o judô, a natação e a ginástica artística. ${ }^{6}$

No que tange às características das modalidades individuais temos, em geral, que as mesmas não exigem ações cooperativas. Além disso, são centradas em provas, podem ter um caráter mais previsível das ações motoras dependendo da modalidade, proporcionam pouca interação entre sujeitos, apresentam uma diversidade de perspectivas e contextos e possuem particularidades e especificidades técnicas. ${ }^{6,11-12}$

O foco das modalidades individuais é o rendimento individual. As mesmas são centras nas técnicas individuais, possuem especificidades estruturais e funcionais, exigem habilidades motoras específicas (técnicas) e movimentos técnicos com alto grau de dificuldade Conexões: revista da Faculdade de Educação Física da UNICAMP, Campinas, v. 13, n. 4, p. 137-154, out./dez. 2015. ISSN: $1983-9030$ 
dependendo da modalidade. Muitas vezes a sua prática envolve a utilização de implementos específicos e exigem capacidades motoras específicas e alto grau de aperfeiçoamento técnico. ${ }^{6,11-12}$

A título de ilustração, será comentado um pouco com relação ao ensino da ginástica. A base motora que constitui os fundamentos da ginástica é conhecida como elementos corporais, os quais são nomeados como deslocamentos, saltos e saltitos, giros e rolamentos, movimentos axiais, balanços e suspensões, ondas, equilíbrios e apoios. Os elementos corporais também constituem a base das demais manifestações ginásticas, tais como a ginástica rítmica (GR), ginástica artística (GA), os esportes acrobáticos, a ginástica de trampolim, a ginástica geral, a ginástica aeróbica, entre outras manifestações ginásticas. O que diferencia estas manifestações é a natureza da sua prática, ou seja, o tipo de aparelho utilizado, a utilização ou não da música e a disposição dos praticantes. ${ }^{6}$

No que se refere à finalidade da prática da GA esta pode ter um caráter educacional e esportivo. É importante frisar que com as adaptações necessárias esses princípios norteadores podem também serem aplicados nas modalidades esportivas coletivas. ${ }^{6}$

Quanto à prática de finalidade educacional ${ }^{6}$ temos:

$\checkmark$ Objetivo: desenvolver habilidades motoras por meio de movimentos ginásticos e caráter formativo;

$\checkmark$ Perfil do praticante: não há requisitos e o ingresso pode acontecer em qualquer idade;

$\checkmark$ Equipamentos utilizados: todo tipo (oficial, adaptado ou não característico da modalidade);

$\checkmark$ Nível de dedicação do sujeito: em geral participa de outras modalidades esportivas (individuais e/ou coletivas);

$\checkmark$ Estrutura de aula/treino: carga horária de no máximo quatro horas/semana. Em geral, aquecimento corporal, preparação corporal geral e específica, alongamento, passagem por aparelhos oficiais com movimentos específicos ou não;

$\checkmark$ Conteúdo: movimentos variados e específicos da modalidade. Não há exigência de alto padrão técnico;

Conexões: revista da Faculdade de Educação Física da UNICAMP, Campinas, v. 13, n. 4, p. 137-154, out./dez. 2015. ISSN: 1983-9030. 
$\checkmark$ Eventos: competições com regras adaptadas e flexíveis. O objetivo é estimular a prática e promover intercâmbio social e esportivo;

$\checkmark$ Postura do professor/técnico: preocupa-se mais com o processo de aprendizagem do que com o produto e a perfeição do movimento final. Aborda a atividade de forma lúdica e espontânea;

$\checkmark$ Resultados: visam estimular a auto-superação e autoavaliação, sem comparações com padrões (modelos);

$\checkmark$ Avaliação do professor/treinador: diária e sem sistematização.

Já quando a finalidade é esportiva ${ }^{6}$ temos:

$\checkmark$ Objetivo: desenvolver habilidades específicas com alta qualidade técnica e caráter competitivo;

$\checkmark$ Perfil do praticante: atletas selecionados de acordo com as qualidades físicas e capacidades motoras sendo a especialização precoce, em geral, entre cinco e seis anos;

$\checkmark$ Equipamentos utilizados: específicos para cada gênero;

$\checkmark$ Nível de dedicação do sujeito: dedicação exclusiva;

$\checkmark$ Estrutura de aula/treino: carga horária de aproximadamente 24 horas/semana. Em geral, aquecimento específico, preparação física geral e específica, treino de flexibilidade e treino específico nos aparelhos oficiais;

$\checkmark$ Conteúdo: elementos específicos da modalidade e exigência de alto padrão técnico de acordo com as regras do código de pontuação;

$\checkmark$ Eventos: competições julgadas por critérios rígidos e preestabelecidos. O objetivo é vencer, conquistar títulos importantes e qualificar-se para eventos cada vez mais expressivos;

$\checkmark$ Postura do professor/técnico: orienta visando o movimento perfeito (ênfase no produto) e é exigente com o treinamento, envolvimento, disciplina e comportamento;

$\checkmark$ Resultados: configuram-se em parâmetros para o ranking de atletas e dependendo da ocasião para qualificar para uma competição superior (Olimpíada, por exemplo);

$\checkmark$ Avaliação: os resultados de competição são os principais meios de avaliação do desempenho. 
Uma das formas para o ensino da GA é por meio dos consagrados padrões básicos do movimento (PBM). O aprendizado dos PBM também promove o desenvolvimento de habilidades para as demais práticas motoras, no esporte e cotidiano, pois estimula o domínio em manejar o próprio corpo. Este sistema de ensino permite a simplificação das ações e uma melhor compreensão de como aplicá-los em situações práticas. Assim teríamos a divisão de conteúdo para ensino através dos PBM, ou seja, aterrissagens, posições estáticas, deslocamentos, rotações, saltos e balanços. ${ }^{6,10}$

O desmembramento das habilidades específicas da GA em PBM facilita o aprendizado, pois permite aprende-los à medida que se desenvolvem as qualidades físicas e motoras e também facilita sua aplicação no contexto de ensino. Quando a habilidade é mais simples, o movimento todo pode ser aplicado até o seu aperfeiçoamento. Para aquelas habilidades mais complexas, por questões de segurança, é altamente recomendado que se pratique por partes. Paralelamente, deve-se realizar um trabalho de preparação corporal e psicológica necessária à realização do movimento. Assim, o praticante vai desenvolvendo a condição física e motora e a autoconfiança para tal realização. Essa alternativa de conteúdo é coerente para orientar os programas de iniciação à GA, pois abrange todas as habilidades possíveis dessa modalidade, simplifica o conteúdo, além de considerar as questões de segurança, pois se trabalha atento à progressão e prontidão do praticante. ${ }^{6,10}$

\section{DIFERENÇAS E SEMELHANÇAS ENTRE AS MODALIDADES ESPORTIVAS COLETIVAS E INDIVIDUAIS}

Em linhas gerais, se fizermos um raciocínio sobre possíveis diferenças e semelhanças entre as modalidades individuais e coletivas, chegaremos a algumas conclusões que podem nos levar a propor diferentes formas de ensino das mesmas. ${ }^{6-7,11-13}$ Com relação às diferenças entre as modalidades individuais e coletivas temos que as individuais:

$\checkmark$ São centradas nas provas diferentemente das modalidades coletivas que são centradas no jogo;

$\checkmark$ O foco é o gesto técnico (ação executada isoladamente) ao invés do fundamento que é o gesto técnico (ação) executado num contexto, no caso o jogo, como nas modalidades coletivas;

Conexões: revista da Faculdade de Educação Física da UNICAMP, Campinas, v. 13, n. 4, p. 137-154, out./dez. 2015. ISSN: 1983-9030. 
$\checkmark$ Tem como foco central mais os componentes técnicos do que os componentes táticos (estratégicos) como nas modalidades coletivas;

$\checkmark$ Dependendo da modalidade o conjunto de ações executadas é mais previsível diferentemente das modalidades coletivas onde as ações motoras possuem um componente de imprevisibilidade predominante (situações-problema);

$\checkmark$ Na maioria das vezes não exigem ações cooperativas como nas modalidades coletivas;

$\checkmark$ Centrada no rendimento individual e não no coletivo. Muito embora o rendimento individual de cada jogador, numa modalidade coletiva, possa interferir no resultado e qualidade do rendimento coletivo.

Com relação às semelhanças entre as modalidades individuais e coletivas ${ }^{6-7,11-13}$ temos que:

$\checkmark$ No seu ensino apresentam e compartilham de habilidades motoras básicas assim como nas modalidades coletivas;

$\checkmark$ Podem trabalhar as mesmas capacidades físicas que nas modalidades coletivas;

$\checkmark$ Em alguns casos é preciso estabelecer relações de oposição (por exemplo, ensino das lutas) como nas modalidades coletivas;

$\checkmark$ Em algumas situações ambas exigem confronto entre equipes;

$\checkmark$ Assim como nas modalidades coletivas onde o foco é a bola algumas modalidades individuais tem como foco adquirir a habilidade de manipulação de um implemento;

$\checkmark$ Possuem regras a serem respeitas como nas modalidades coletivas;

$\checkmark$ Em geral, possuem um terreno delimitado no qual acontecem as atividades como nas modalidades coletivas.

\section{ÚLTIMAS PALAVRAS}

Com relação aos possíveis caminhos para o ensino de modalidades esportivas poderíamos destacar que é importante respeitar os conteúdos das fases do processo de aprendizagem, diversificar a aprendizagem dentro da modalidade a ser ensinada e introduzir no processo o estímulo das habilidades motoras básicas. ${ }^{10}$ Além disso, o professor de educação física poderia estimular a aprendizagem por meio de processos que envolvam todos os sentidos, Conexões: revista da Faculdade de Educação Física da UNICAMP, Campinas, v. 13, n. 4, p. 137-154, out./dez. 2015. ISSN: 1983-9030. 
incrementar o processo de ensino através do estímulo das inteligências múltiplas e pautar o ensino do esporte na solução de problemas, ou seja, numa prática com significado funcional. ${ }^{11-12}$ Outro fator importante é a transmissão de saberes sobre o esporte ensinado como, por exemplo, a inclusão de conteúdos sobre a modalidade (dimensões comportamental, biológica e sociocultural) que favoreçam o reconhecimento e a interpretação das demandas das tarefas (comportamental), do organismo (biológica) e do ambiente (físico e sociocultural). ${ }^{6}$

Além disso, é importante ter cuidado e evitar, por exemplo, uma prática repetitiva de gestos técnicos em diferentes níveis de ensino, por exemplo, o voleibol praticado no quinto ano do ensino fundamental é o mesmo que o praticado no sexto, sétimo, oitavo e etc. Tomar cuidado com a fragmentação de conteúdos, ou seja, o esporte é oferecido de forma desorganizada e sem respeito à evolução necessária ao aprendizado e a especialização esportiva precoce. ${ }^{6-7,13}$

Em resumo, um dos objetivos do esporte é a formação para a vida. A prática esportiva proporciona muito mais do que títulos e medalhas, ou seja, desperta qualidades como cooperação, perseverança, socialização, respeito e demais atitudes positivas que contribuirão para a convivência em sociedade. ${ }^{6}{ }^{9}$ Cabe aos futuros profissionais de educação física conhecer as ferramentas, a teoria pedagógica associada ao esporte, para serem capazes de identificar e desenvolver todo o potencial das pessoas através do esporte.

\section{REFERÊNCIAS}

${ }^{1}$ DAIUTO, M. Basquete: metodologia do ensino. 6. ed. São Paulo: Hemus, 1991.

${ }^{2}$ DELORS, J. (Coord.). Educação: um tesouro a descobrir: relatório para a Unesco da Comissão Internacional sobre Educação para o Século XXI. São Paulo: Cortez, 1999.

${ }^{3}$ FREIRE, P. Pedagogia da anatomia: saberes necessários à prática educativa. São Paulo: Paz e Terra, 1996.

${ }^{4}$ GHIRALDELLI JÚNIOR, P. O que é pedagogia. 3 ed. São Paulo: Brasiliense, 1996. Conexões: revista da Faculdade de Educação Física da UNICAMP, Campinas, v. 13, n. 4, p. 137-154, out./dez. 2015. ISSN: 1983-9030. 
${ }^{5}$ GIACOMIN, T. M. Temas gerais em educação e pedagogia. Aracruz: Facha, 1999.

${ }^{6}$ TANI, G.; BENTO, J. O.; PETERSEN, R. D. S. Pedagogia do desporto. Rio de Janeiro: Guanabara Koogan, 2006.

${ }^{7}$ PAES, R. R.; BALBINO, H. F. Pedagogia do esporte: conceitos e perspectivas. Rio de Janeiro: Guanabara Koogan, 2005.

${ }^{8}$ BARBANTI, V. J. Dicionário de educação física e esporte. 2 ed. Barueri: Manole, 2003.

${ }^{9}$ TUBINO, M. J. G. Estudos brasileiros sobre o esporte: ênfase no esporte-educação. Maringá: Eduem, 2010.

${ }^{10}$ CANFIELD, I. M. Aprendizagem motora. Santa Maria: Gráfica da UFSM, 1981.

${ }^{11}$ GRECO, P. J. Iniciação esportiva universal II: metodologia da iniciação esportiva na escola e no clube. Belo Horizonte: Ed. UFMG, 1998.

${ }^{12}$ GRECO, P. J.; BENDA, R. N. Iniciação esportiva universal I: da aprendizagem motora ao treinamento técnico. Belo Horizonte: Ed. da UFMG, 1998.

${ }^{13}$ TEODORESCU, L. Problemas de teoria e metodologia nos jogos desportivos. Lisboa: Livros Horizonte, 1984.

Recebido em: 19 out. 2015 Aceito em:21 nov. 2015 Contato: rodrigoluizvancini@gmail.com 